\title{
Generation of High-Titer Defective HSV-1 Vectors Using an IE 2 Deletion Mutant and Quantitative Study of Expression in Cultured Cortical Cells
}

BioTechniques 20:460-469 (March 1996)

F. Lim, D. Hartley, P. Starr, P. Lang, S. Song, L. Yu, Y. Wang and A.I. Geller ${ }^{1}$

Children's Hospital and

${ }^{1}$ Harvard Medical School, Boston, MA, USA

\section{ABSTRACT}

Vectors based on herpes simplex virus type 1 (HSV-1) show promise for gene transfer into mammalian cells because of their wide host range, efficient infection and ability to deliver genes to nondividing cells. Defective HSV-1 vectors, or amplicons, are plasmid vectors which are unable to propagate on their own but contain specific HSV1 sequences that, in the presence of helper virus, support DNA replication and subsequent packaging into virus particles. We compared three replication-incompetent HSV-1 mutants (KOS strain 5d11.2, strain 17 D30EBA, KOS strain d120) as the helper virus for packaging the prototype defective HSV-1 vector, pHSVlac, which uses the HSV-1 immediate-early (IE) 4/5 promoter to regulate expression of the Escherichia coli lacZ gene. Use of $5 \mathrm{dl} 1.2$, which contains a deletion in the IE 2 gene, consistently produced virus stocks that contained a high level of vector, undetectable levels of wild-type HSV-1 and a ratio of vector to helper greater than 1. Virus stocks prepared using $5 \mathrm{~d} 11.2$ were superior to those prepared using helper viruses that harbor a deletion in the IE 3 gene, either D3OEBA or d120, and supported more efficient gene transfer than possible with previously published procedures. Lactate dehydrogenase efflux assays in rat cortical cultures showed that $5 \mathrm{~d} 11.2$ was no more cytotoxic than either D30EBA or 1120 , despite the expres sion of more viral genes. Rat cortical cultures infected with pHSVlac packaged with either $5 \mathrm{~d} 11.2$ or D3OEBA were used to quantify the stability of vector expression. Our results show a decrease in the number of cells with detectable levels of $\beta$-galactosidase to $30 \%$ of peak levels after one week, irrespective of the helper virus used. However, simultaneous superinfection with $5 \mathrm{dl} 1.2$, but not with either D30EBA or d120, produced a transient increase in the number of cells expressing $\beta$-galactosidase. Superinfection with $5 \mathrm{~d} 11.2$ at 9 days after gene transfer increased the number of cells expressing detectable $\beta$-galactosidase back to peak levels, most probably because of reactivation of the IE $4 / 5$ promoter in pHSVlac. These results thus provide the first quantitative demonstration of long-term persistence of defective $H S V-1$ vectors in neurons.

\section{INTRODUCTION}

For gene transfer into quiescent or postmititotic cells, particularly those in the brain, herpes simplex virus type 1 (HSV-1) exhibits a number of desirable characteristics that include a wide hostcell range, the capability to infect nondividing cells, a long-term persistence and the capacity to accommodate large molecules of foreign DNA (for review see Reference 35). There are two types of replication-incompetent HSV-1 vectors: those based on recombinant viral genomes $(8,11)$ and defective HSV-1 vectors $(14,33)$, which are composed of a plasmid, or amplicon, which is packaged into virus particles in the presence of a helper virus. Defective HSV-1 vectors contain the HSV-1 sequences necessary for replication (an origin of DNA replication) and packaging (an a sequence) and can be manipulated easily by standard recombinant DNA techniques. Consequently, there has been a growing interest in their potential uses in gene transfer experiments.

Defective HSV-1 vectors have been used to perturb neuronal physiology both in culture $(1,2,15,19,36)$, and in the rat brain $(9,19)$. These initial physiological experiments, while encouraging, have also illuminated the limitations of the current packaging system. In theory, by using a sufficient amount of vector, it should be possible to genetically modify virtually all of the target cells. However, with the present HSV-1 vector systems, cytotoxic effects associated with the systems place an upper limit on the concentrations of vector that can be used. In spite of the inability of replication-incompetent helper viruses to progress through the lytic cycle in normal cells, cytopathic effects can result both from proteins present in HSV-1 particles and from expression of HSV-1 immediate-early (IE) genes (20). In addition, during the packaging of defective HSV-1 vectors using 
specific helper viruses, wild-type (wt) HSV-1 revertants arise at a finite frequency $(16,20)$ and contribute to the cytotoxicity. Consequently, to reduce the cytopathic effects of defective HSV1 vectors, two of the goals of this study were to increase the proportion of the vector with respect to both the helper virus and wt HSV-1.

Specific replication-incompetent HSV-1 mutants are available as candidates for the helper virus to package defective HSV-1 vectors. Of the five IE genes, only IE 2 (ICP27 or Vmw63) and IE 3 (ICP4 or Vmw175) are required for the lytic cycle of HSV-1 (reviewed in Reference 35). Past work in our laboratory as well as others' has concentrated on the use of IE 3 mutants as helper viruses since IE 3 mutants have a restrictive phenotype in that under nonpermissive conditions they express few HSV-1 genes $(6,27)$. However, the titers of IE 3 deletion mutants obtained in cultured fibroblasts are reduced compared with wt HSV-1. Therefore, we examined the effectiveness of an IE 2 deletion mutant as the helper virus in the packaging procedure.

The prototype-defective HSV-1 vector, pHSVlac, uses the IE 4/5 promoter to regulate expression of the Escherichia coli lacZ gene, and many other vectors also use the HSV-1 IE 4/5 promoter to direct recombinant gene expression. Within the context of the HSV-1 genome, this promoter appears to be inactive during latency (reviewed in Reference 35). In contrast, in transgenic mice, the IE 3 promoter is active in at least some cell types in the adult brain (24), defective HSV-1 vectors harboring three different IE promoters support long-term expression in cultured peripheral neurons (32) and, in the adult rat brain, injection of defective vectors containing the IE $4 / 5$ promoter results in expression in at least some striatal cells for up to one year (9). Therefore, we undertook a quantitative study of the stability of expression from pHSVlac in cultured cortical neurons. Also, since many more viral proteins are expressed by IE 2 mutants compared with IE 3 mutants, we investigated the effects of an IE 2 deletion mutant helper virus on recombinant gene expression.

\section{MATERIALS AND METHODS}

\section{Cell Culture and Virus Growth}

Cell lines were cultured in Dulbecco's modified essential medium (DMEM) supplemented with penicillin/streptomycin (both from Life Technologies, Gaithersburg, MD, USA) and $4 \mathrm{mM}$ glutamine at $37^{\circ} \mathrm{C}$ in humidified incubators containing $5 \%$ $\mathrm{CO}_{2}$. PC-12 cells (18) were grown in $10 \%$ horse serum (HS) and 5\% fetal bovine serum (FBS) (both from Life Technologies), and NIH3T3 mouse fibroblasts were grown in DMEM containing $10 \%$ calf serum. DMEM containing 10\% FBS was used for all other cell lines including 2-2 cells (31); VERO cells which contain the IE 2 gene; E5 cells (7); VERO cells which contain the IE 3 gene; RR1 cells (20) and M64A cells (5); BHK cells which contain the IE 3 gene; MN9D cells (4), a cell line derived from the human mesencephalon, which has some characteristics of a catecholaminergic central nervous system neuron; and CV-1 and BHK-21 monkey fibroblasts.

Dissociated rat cortical cell cultures containing a mixture of neurons and glia were prepared from postnatal rats (days 1-2) by standard methods (22) with the following modifications: cells were plated into poly-D-lysine-treated 24 -well plates $\left(3.8 \times 10^{5}\right.$ cells per well $)$ in DMEM supplemented with $10 \%$ heat-inactivated FBS, $4 \mathrm{mM}$ glutamine, $21 \mathrm{mM}$ glucose and $38 \mathrm{mM} \mathrm{NaHCO}$. The cultures were maintained at $37^{\circ} \mathrm{C}$ in a humidified incubator containing $5 \% \mathrm{CO}_{2}$. After 1 week, cell replication was inhibited by exposure to $10^{-5} \mathrm{M}$ cytosine arabinoside (Sigma Chemical, St. Louis, MO, USA) for 1 day, after which the medium was replaced with DMEM containing $1 \%$ heat-inactivated HS. Cultures were used for experiments after 14 days.

The wt HSV-1 strain $17^{+}$(3) was grown on BHK- 21 cells. The HSV-1 strain $17^{+}$IE 3 deletion mutant D30EBA (27) was grown initially on M64A cells, but since this gave rise to revertants at a significant frequency (between $10^{-5}$ and $10^{-4}$ ), the virus was later grown on RR 1 cells. The IE 3 deletion mutant $\mathrm{d} 120(6)$, derived from the KOS strain (30), was grown on E5 cells; and the IE 2 deletion mutant $5 d l 1.2$ (23), also derived from KOS strain, was grown on 2-2 cells.

The wt HSV-1 strain $17^{+}$was assayed on BHK- 21 and CV- 1 cells, the IE 2 deletion mutant virus $5 d l 1.2$ was assayed on 2-2 cells and the IE 3 deletion mutant viruses d120 and D30EBA were assayed on E5 cells. Plaque assays were performed by standard methods (34).

Titers of vectors were measured on PC-12 cells (14) with the following modifications: 24-well plates were coated with poly-D-lysine $(500 \mu \mathrm{L}$ of $20 \mu \mathrm{g} / \mathrm{mL}$ aqueous solution, $10 \mathrm{~min}$ ), and after removal of the coating solution, $\mathrm{PC}-12$ cells were plated at $5 \times 10^{5}$ cells per well. The next day the cells were infected, and 1 day later the cells were fixed in $4 \%$ paraformaldehyde,

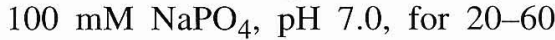
min. The cells were washed once with PBS $\left(1.5 \mathrm{mM} \quad \mathrm{KH}_{2} \mathrm{PO}_{4}, 13.5 \mathrm{mM}\right.$ $\mathrm{Na}_{2} \mathrm{HPO}_{4}, 2.7 \mathrm{mM} \mathrm{KCl}$ and $137 \mathrm{mM}$ $\mathrm{NaCl})$ and once with GST (2\% goat serum and $0.2 \%$ Triton ${ }^{\circledR}$ X-100 in PBS). Detection of $\beta$-galactosidase in situ was performed essentially as previously described (29) by incubating the cells at $37^{\circ} \mathrm{C}$ for $24 \mathrm{~h}$ in PBS containing $5 \mathrm{mM}$ potassium ferricyanide, 5 $\mathrm{mM}$ potassium ferrocyanide, $1 \mathrm{mM}$ $\mathrm{MgCl}_{2}, 0.02 \%$ Nonidet ${ }^{\circledR}$ P-40, $0.01 \%$ sodium deoxycholate and $1 \mathrm{mg} / \mathrm{mL} 5$ bromo-4-chloro-3-indolyl- $\beta$-D-galactoside (X-gal; Sigma Chemical). Titers of vector were expressed as infectious particles $/ \mathrm{mL}$.

\section{Lactate Dehydrogenase Efflux Assays}

As an indication of cell death in cortical cultures, extracellular lactate dehydrogenase (LDH) enzyme activity was measured as described by Koh and Choi (22). Briefly, $24 \mathrm{~h}$ after infection, $75 \%$ of the medium in each well of a 24-well plate $(400 \mu \mathrm{L})$ was replaced with HBCSS, pH 7.4 (86.5 mM NaCl, $5.4 \mathrm{mM} \mathrm{KCl}, 0.8 \mathrm{mM} \mathrm{MgCl} 2,1.8 \mathrm{mM}$ $\mathrm{CaCl}_{2}, 20 \mathrm{mM}$ glucose, $20 \mathrm{mM}$ HEPES, $26 \mathrm{mM} \mathrm{NaHCO}$ and $10 \mathrm{mM}$ $\mathrm{NaOH}$ ). After 3 consecutive medium exchanges, the cells were returned to the incubator, and LDH assays were performed at both 4 and 7 days after infection as follows: $50-\mu \mathrm{L}$ aliquots of 
the culture medium were added to a $\mathrm{NADH}$ /pyruvate mixture, and the change in absorbance at $340 \mathrm{~nm}$ was monitored. Enzyme units were calibrated using purified LDH (Sigma Chemical).

\section{Packaging of Defective HSV-1 Vectors}

Two days before transfection, cells were trypsinized and seeded at $3 \times 10^{5}$ cells per $60-\mathrm{mm}$ dish in $5 \mathrm{~mL}$ DMEM containing $10 \%$ FBS. For each transfection sample, $2 \mu \mathrm{g}$ plasmid DNA were diluted to $100 \mu \mathrm{L}$ with OPTI$\mathrm{MEM}^{\circledR}$ and mixed with $100 \mu \mathrm{L}$ OPTIMEM containing $12 \mu \mathrm{L}$ Lipofectamine $^{\mathrm{TM}}$ (both from Life Technologies). After allowing liposome formation for $20 \mathrm{~min}$ at room temperature, OPTIMEM was added to a final volume of 3 $\mathrm{mL}$, and the mixture was overlaid onto the cells that had been washed once with OPTI-MEM. The cells were incubated for $5 \mathrm{~h}$ at $37^{\circ} \mathrm{C}$ and washed 3 times with PBS, once with DMEM containing $10 \% \mathrm{FBS}$, and then $5 \mathrm{~mL}$ DMEM containing 10\% FBS were added. On the next day, at least $20 \mathrm{~h}$ after the PBS washes, the medium was removed and replaced with $5 \mathrm{~mL}$ DMEM containing 5\% FBS containing approximately $6 \times 10^{5}$ plaque-forming units (pfu) of helper virus. One day later, the cells were checked for cytopathic effects and harvested by scraping the cells into the culture medium. The virus (4 mL) from this initial transfection/infection, designated $\mathrm{p} 0$, was passaged on fresh cells 3 times to increase both the ratio of vector to helper and the total amount of virus. For each passage, the cells were seeded 2 days prior to infection at the following densities: $\mathrm{p} 1,1$ plate per sample at $4 \times 10^{5}$ cells per 60 mm plate; p2, 2 plates per sample at $1 \times$ $10^{6}$ cells per $100-\mathrm{mm}$ plate; and p3, 4 plates per sample at $1 \times 10^{6}$ cells per $100-\mathrm{mm}$ plate. The volumes of virus used to infect the respective passages were $4 \mathrm{~mL}$ p0 diluted with $4 \mathrm{~mL}$ DMEM containing 5\% FBS; $8 \mathrm{~mL}$ p1 diluted with $12 \mathrm{~mL}$ medium; and 16 $\mathrm{mL}$ p2 diluted with $24 \mathrm{~mL}$ medium.

\section{Virus Purification}

Virus was purified as described (34) with the following modifications: virus (20 mL of p3). was centrifuged through a discontinuous sucrose gradient consisting of $7 \mathrm{~mL}$ of $60 \%$ sucrose, $6 \mathrm{~mL}$ of $30 \%$ sucrose and $3 \mathrm{~mL}$ of $10 \%$ sucrose in a $40-\mathrm{mL}$ Beckman Instruments (Fullerton, CA, USA) SW28 ultracentrifuge tube. Sucrose solutions were made using sterile PBS and stored at $4^{\circ} \mathrm{C}$. After centrifugation for $1 \mathrm{~h}$ at $125000 \times g$, the virus at the interface between the $30 \%$ and $60 \%$ sucrose solutions was collected in a volume of approximately $2 \mathrm{~mL}$. After dilution with approximately $18 \mathrm{~mL} \mathrm{PBS}$, the virus was centrifuged at $125000 \times g$ for $1 \mathrm{~h}$. The pellet was resuspended in $200 \mu \mathrm{L}$ $\mathrm{PBS} / 10 \%$ sucrose and stored in aliquots at $-70^{\circ} \mathrm{C}$.

\section{RESULTS}

\section{Use of an IE 2 Deletion Mutant as the Helper Virus}

The structures of the 3 deletion mutant viruses used in this study and the cell lines used for their growth are shown in Figure 1. Two of the mutants, D30EBA (27) and d120 (6), contain a deletion in the IE 3 gene, while the third mutant, $5 d l 1.2$ (23), harbors a deletion in the IE 2 gene. Previous work in our laboratory (16) was carried out using D30EBA grown on M64A cells. Our first aim in optimizing the packaging of defective HSV-1 vectors

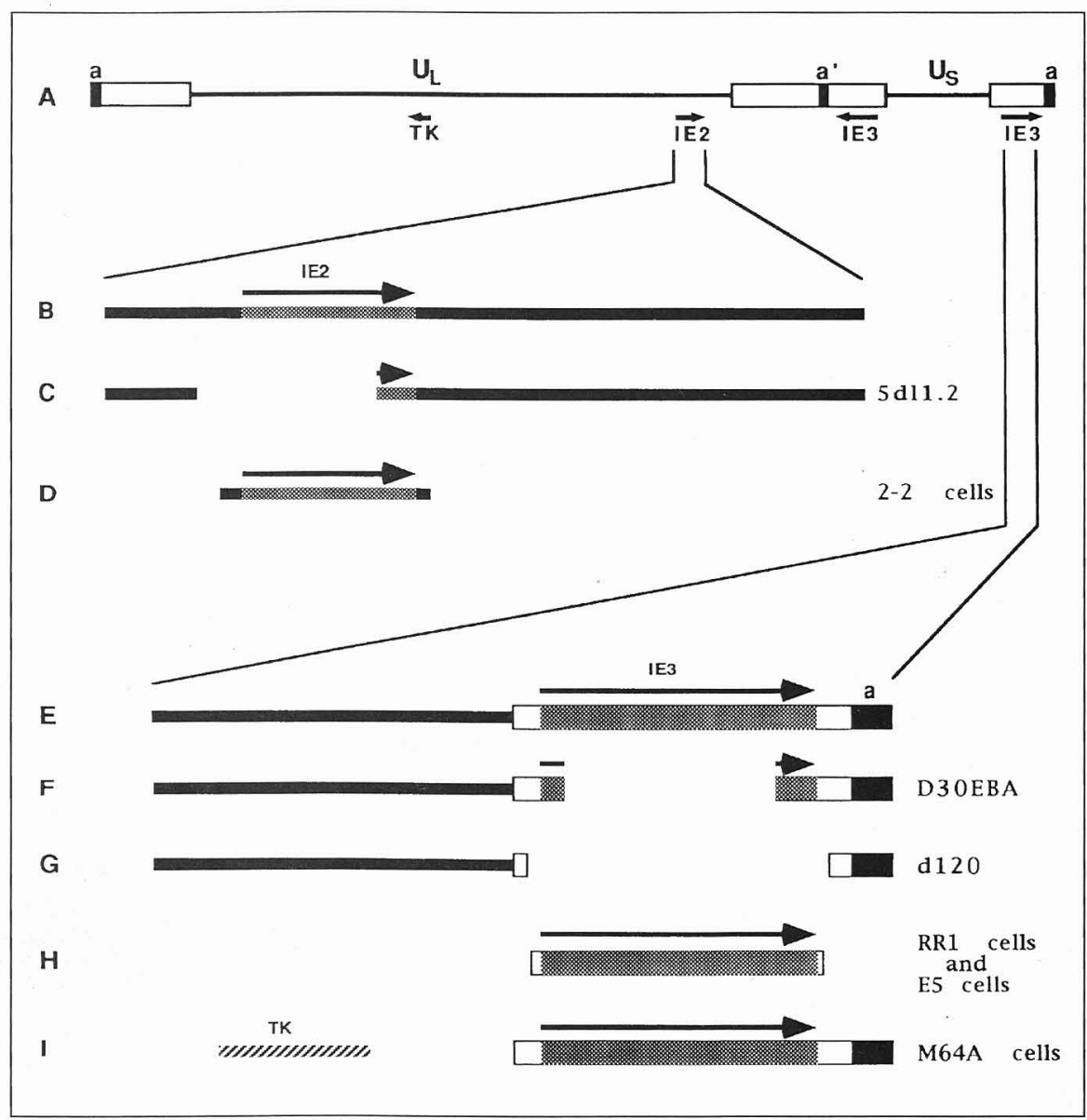

Figure 1. Schematic representations of the different deletion mutant helper viruses used in this study and their complementing cell lines. (A) The relative positions and orientations of the thymidine kinase gene (TK), the IE 2 and IE 3 genes, and the a sequences (filled boxes) within the HSV-1 genome are shown. The unique long $\left(\mathrm{U}_{\mathrm{L}}\right)$ and unique short $\left(\mathrm{U}_{\mathrm{S}}\right)$ regions are shown as solid lines and are flanked by the repeat sequences that are represented as boxes. (B) Enlargement of the region surrounding the IE 2 gene. (C) The deleted sequences of the IE 2 gene in the $5 d l 1.2$ virus. (D) The fragment of HSV-1 DNA integrated into the genome of 2-2 cells. (E) Enlargement of the region surrounding the IE 3 gene. Only one of the two copies is shown. (F and G) The deleted sequences of the IE 3 gene in D30EBA and d120, respectively. (H) The fragments of HSV-1 DNA integrated into the genomes of RR1 and E5 cells. (I) M64A cells. 
was to reduce the levels of wt HSV-1. Since growth of D30EBA on M64A cells gives rise to wt revertants at a relatively high rate $\left(10^{-5}\right.$ to $\left.10^{-4}\right)$, we replaced M64A cells with RR1 cells (20). Within the sensitivity of our pfu assay $\left(10^{-6}\right)$, we rarely detected any wt HSV1 revertants in any of the virus stocks grown for up to 3 serial passages on RR1 cells. Similar results were obtained in packaging experiments that used $\mathrm{d} 120$ as the helper virus, which was grown on E5 cells (7), or $5 d l 1.2$ as the helper virus, which was grown on 2-2 cells (31). In one experiment using $5 d l 1.2$ as the helper virus, no wt HSV- 1 was observed even after 10 serial passages. However, in approximately 5\% of the virus stocks, we observed wt HSV-1 at a frequency of approximately $10^{-6}$. These much lower levels of wt HSV-1 have allowed increased amounts of vectors to be used in physiological experiments with cultured neurons compared with vectors packaged with D30EBA. Furthermore, no rats died from HSV encephalitis (data not shown) following injection of vectors packaged using d 120 or $5 d l 1.2$, although injection into the adult rat brain of vectors packaged using D30EBA resulted in death of a significant fraction of the rats within 2 weeks following gene transfer.

Our next goal was to improve the packaging procedure to consistently obtain both a high titer of vector $\left(\geq 10^{6} / \mathrm{mL}\right)$ and a favorable ratio of vector to helper $(\geq 1)$. Two modifications were made: first, we found that transfection of the vector DNA was found to be more efficient and reproducible using the Lipofectamine method in place of the calcium phosphate method, and second, we noted that use of the IE 2 deletion mutant $5 d l 1.2$ as the helper virus yielded vector titers that were consistently higher. than we had previously observed with either of the IE 3 deletion mutants D30EBA or d120. The titers from a representative experiment in which pHSVlac was packaged using either $5 d l 1.2$ or $\mathrm{d} 120$ as the helper virus is shown in Figure 2. The number of infectious particles of pHSVlac present at each passage during the packaging was higher using 5 dl1.2 compared with d120 (Figure 2a). Better growth of pHSVlac with succeeding passages using $5 d l 1.2$ also resulted in poorer growth of the helper virus (Figure 2b). Thus, the principal advantage of using $5 d l 1.2$ as the helper virus was a higher ratio of vector to helper (Figure 2c). Using D30EBA, we can sometimes produce some virus stocks that contain a vector to helper virus ratio of $\geq 1: 1$, but we have as yet been unable to determine the critical parameters. In contrast, using this procedure, packaging vectors using $5 d l 1.2$ as the helper virus on 2-2 cells appear to reproducibly yield virus stocks that contain a high ratio of vector to helper virus.

Our prototype vector pHSVlac packaged using $5 d l 1.2$ as the helper virus was used to infect several different fibroblast cell lines including CV-1, VERO-E5, BHK-21 and NIH/3T3. Since our primary interest in the HSV1 vector system is to transfer genes into the cells of the nervous system, we also

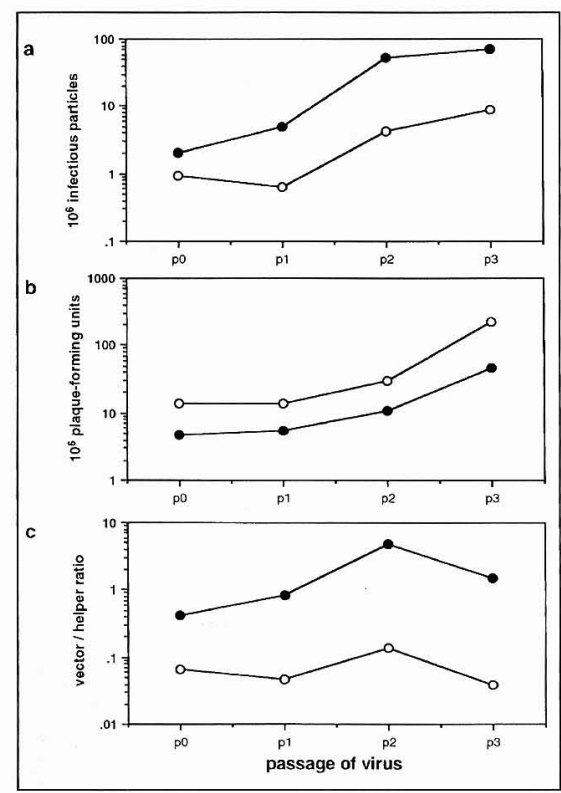

Figure 2. Comparison of packaging efficiency obtained by using an IE 2 or and IE 3 deletion mutant as the helper virus. The prototype vector pHSVlac was packaged using either the IE 2 deletion mutant $5 d l 1.2$ (filled circles) or the IE 3 deletion mutant $\mathrm{d} 120$ (open circles). Aliquots from serial passages (p0, p1, p2 and p3) of each virus stock were titered for both vector (infectious particles) and helper virus (pfu). (a) Titers of pHSVlac were measured on PC-12 cells using the X-gal assay for $\beta$-galactosidase activity. (b) Titers of $5 d l 1.2$ and d 120 helper viruses were determined on 2-2 cells and E5 cells, respectively. (c) The ratio of vector to helper. The passage p0 refers to the virus harvested from the initial transfection/infection step of the packaging procedure. tested two cell lines showing neuronal characteristics, PC-12 and MN9D cells. One day after infection, efficient expression of $\beta$-galactosidase was observed in all 6 of these cell lines (results not shown); these results are similar to those previously obtained $(13,16)$ using pHSVlac packaged using helper viruses that harbor a mutation in the IE 3 gene (ts $\mathrm{K}$ or D30EBA).

\section{Cytotoxicity Caused by IE 2 and IE 3 Deletion Mutant Viruses}

Since we are using HSV-1 vectors for gene transfer, into neurons, we investigated the cytotoxic effects of the 3 deletion mutant helper viruses in primary rat cortical cultures. The efflux of lactate dehydrogenase (LDH) enzyme activity from injured cells into the culture medium has been used to quantify damage to cortical neuronal cultures (22). Thus, the effects of infection by D30EBA, d120 or $5 d l 1.2$ on extracellular LDH levels in cultured cortical cells were investigated. Four days after

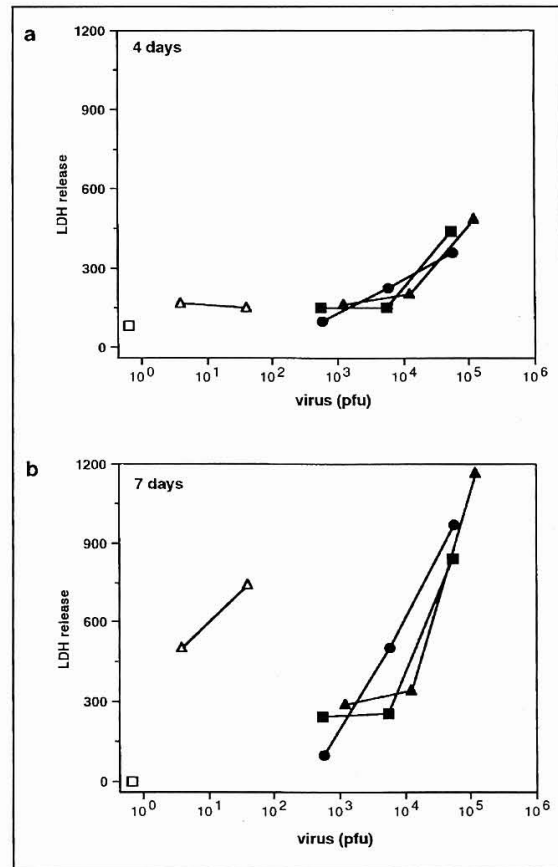

Figure 3. Cytotoxicity of wt HSV-1 and viruses harboring deletions in either the IE 2 or the IE 3 gene. Supernatants from uninfected cortical cultures (open squares) or cultures infected with increasing amounts of wt HSV-1 (open triangles), D30EBA (solid triangles), d120 (solid squares) or $5 d l 1.2$ (solid circles) were assayed for lactate dehydrogenase (LDH) activity at 4 (a) or 7 (b) days after infection. LDH activity is expressed in enzyme units. 
Circle Reader Service No. 214

infection, amounts of less than $10^{4} \mathrm{pfu}$ per well of any of the 3 replication-incompetent helper viruses or less than $100 \mathrm{pfu}$ per well of strain $17 \mathrm{wt}$ virus caused minimal LDH efflux (Figure
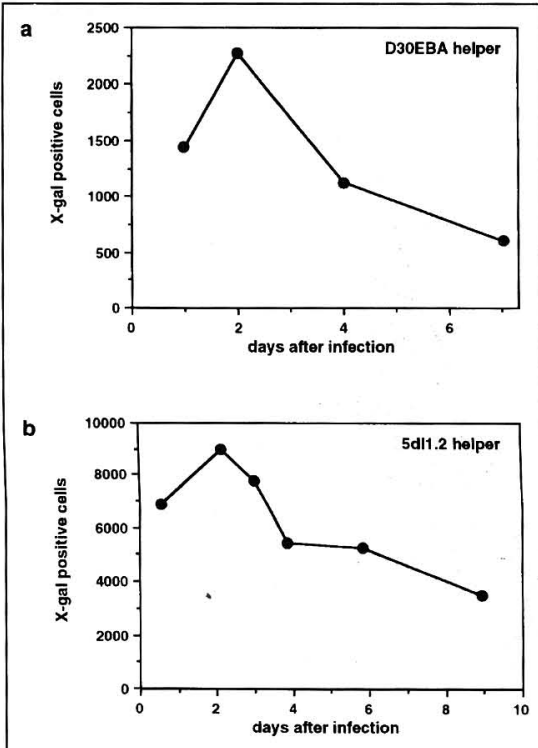

Figure 4. Expression of $\beta$-galactosidase from pHSVlac in cultured cortical cells over a 1week period. Cultures were infected with pHSVlac packaged either with D30EBA (a) or $5 d l 1.2(\mathrm{~b})$, and at the indicated times the number of cells expressing $\beta$-galactosidase was determined using $X$-gal staining. 3a). However, 7 days after infection, cultures infected with less than $10 \mathrm{pfu}$ per well of wt HSV-1 showed obvious signs of cell damage by visual examination and exhibited elevated levels of extracellular LDH (Figure 3b). At this time point, D30EBA, d120 and $5 d l 1.2$ all exhibited similar toxicity profiles, and at approximately 1000 -fold higher concentrations than wt HSV-1, they directed levels of $\mathrm{LDH}$ release similar to wt HSV-1. These data suggest that differences in gene expression between the 3 replication-incompetent helper viruses do not result in large differences in their cytotoxicity. However, small amounts of wt HSV-1 revertants initially present in vector stocks (e.g., those made with D30EBA grown on M64A cells) would have a much larger contribution to cytotoxicity since wt HSV-1 not only causes more drastic cytopathic effects but is also able to replicate and increase in concentration.

\section{$\beta$-Galactosidase Expression from pHSVlac in Cultured Cortical Cells}

Cultured cortical cells were infected with pHSVlac, and the number of cells expressing $\beta$-galactosidase was determined at various times after gene trans- fer (Figure 4). Similar expression profiles were obtained using pHSVlac packaged with either D30EBA (Figure $4 a)$ or $5 d l 1.2$ (Figure 4b). After an initial rise to peak expression at 2 days after infection, we observed a decrease in the number of positive cells down to about $30 \%$ of peak levels after a week. This decrease in the number of positive cells could be due to multiple effects including death of cells containing the vector, loss of vector DNA from the cell or reduced expression of the lacZ gene. Although we observed some cell death, particularly when higher amounts of virus stocks were added to the cultures, the decrease in the cell number could not account for the larger decrease in the number of cells expressing $\beta$-galactosidase. Although IE promoters are active in stably transformed fibroblasts $(26,28)$, in some cells in transgenic mice $(24,25)$, in cultured sensory neurons (32) and in at least some cells in the adult brain $(9,33)$ following gene transfer by this vector system, IE promoters are not active in a latent HSV-1 infection. Thus, a possible explanation for diminished expression of $\beta$-galactosidase with time after infection is shutdown of the IE $4 / 5$ promoter. 


\section{Activation of the IE 4/5 Promoter in pHSVlac by Superinfection with $5 d l 1.2$ Virus}

The IE 4/5 promoter fragment present in pHSVlac contains a binding site for the IE 3 gene product, and therefore, its activity may be influenced by IE 3 protein. We tested this hypothesis by using either D30EBA, d120 or $5 d l 1.2$ to coinfect neurons with pHSVlac. pHSVlac packaged with either $5 d l 1.2$ or D30EBA was used to infect neurons at a low multiplicity of infection (MOI), and then increasing amounts of D30EBA, d120 or $5 d l 1.2$ were added. On the following day, the number of cells expressing $\beta$-galactosidase was determined (Figure 5). Coinfection with $5 d l 1.2$ increased the number of cells expressing $\beta$-galactosidase irrespective of the helper virus used, whereas both $\mathrm{d} 120$ and D30EBA had a minimal effect. Previous studies using $\mathrm{CV}-1$ or PC-12 cells infected with pHSVlac packaged using ts $\mathrm{K}$, an HSV1 strain bearing a temperature-sensitive mutation in the IE 3 gene, have indicated that $\mathrm{ts} \mathrm{K}$ had a minimal effect on

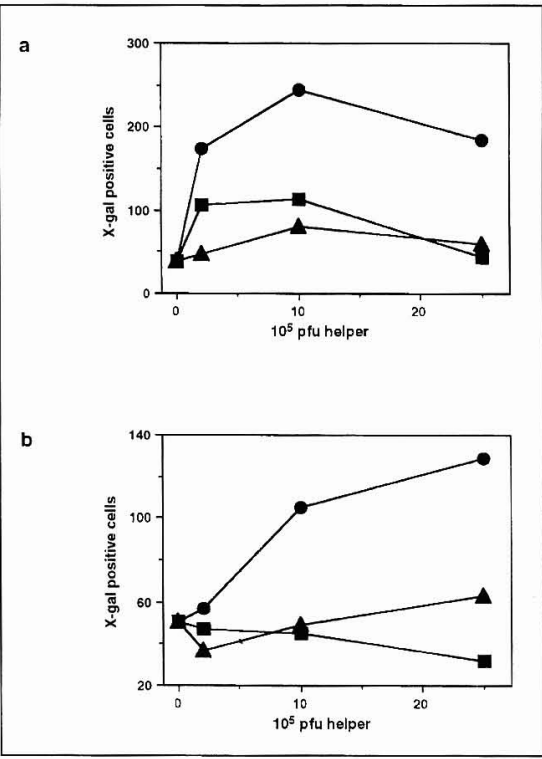

Figure 5. Influence of superinfection with either IE 2 or IE 3 deletion mutant viruses on expression of $\beta$-galactosidase from pHSVlac in cultured cortical cells. Cultures were infected with pHSVlac packaged using either D30EBA (a) or $5 d l 1.2$ (b). The cultures were immediately superinfected with increasing amounts of D30EBA (triangles), d120 (squares) or $5 d l 1.2$ (circles), and 1 day later the number of cells expressing $\beta$-galactosidase was determined using $\mathrm{X}$-gal staining. expression of $\beta$-galactosidase (13). Virus $5 d l 1.2$, which contains a deletion in IE 2, supports expression of more HSV-1 genes in nonpermissive cells compared with viruses harboring mutations in IE 3. Thus, while our results suggest that the IE 3 gene product promotes transcription of the IE $4 / 5$ promoter, further work is needed to determine if this is a direct or indirect effect. The modest enhancement of vector expression sometimes obtained by coinfection with IE 3 deletion mutants (e.g., Figure 5a with d120, and Figure $7 b$ with D30EBA) indicates that activation of the IE $4 / 5$ promoter may also be evoked by other events associated with HSV-1 infection.

The stability of the induction of $\beta$ galactosidase expression by $5 d l 1.2$ was investigated. Cultures infected with pHSVlac packaged using $5 d l 1.2$ were superinfected with increasing amounts of $5 d l 1.2$, while cultures infected with

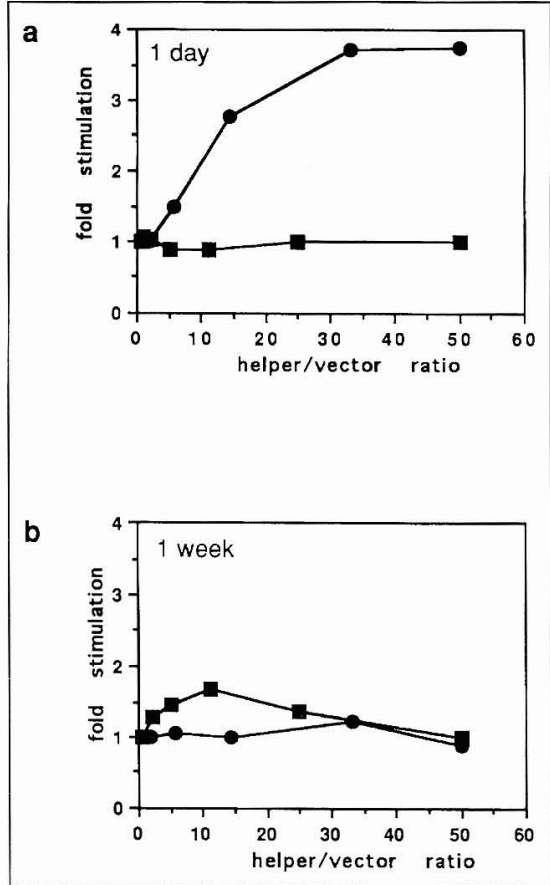

Figure 6. Superinfection with an IE 2 deletion mutant causes a transient enhancement of $\beta$ galactosidase expression from pHSVlac. $\mathrm{Cul}$ tured cortical cells were infected with pHSVlac packaged using either D30EBA (squares) or $5 d l 1.2$ (circles). One day (a) or 1 week (b) after infection, the cultures were superinfected with increasing amounts of the same helper virus used in the packaging, and 1 day later the number of cells expressing $\beta$-galactosidase was determined using $\mathrm{X}$-gal staining. The results are expressed as the fold stimulation relative to cultures that were not subjected to superinfection.
pHSVlac packaged using D30EBA were superinfected with increasing amounts of D30EBA. One and seven days later, the cultures were assayed for expression of $\beta$-galactosidase (Figure 6). The enhancement of expression caused by superinfection with $5 d l 1.2$ was no longer present after one week. These data are consistent with the transient nature of HSV-1 gene expression following $5 d l 1.2$ infection of nonpermissive cells and indicate that the activity of the IE $4 / 5$ promoter may be

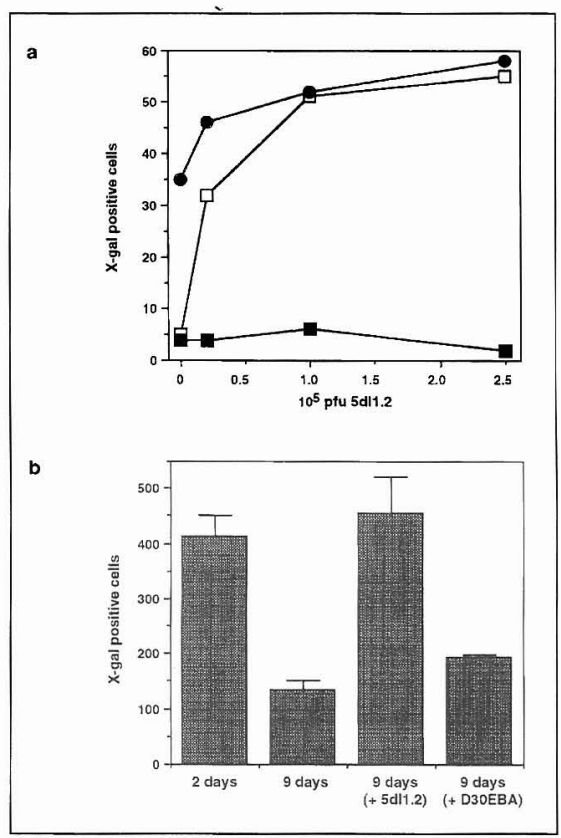

Figure 7. Long-term persistence of pHSVlac DNA in cultured cortical cells can be revealed by reactivation of $\beta$-galactosidase expression following superinfection with an IE 2 deletion mutant virus. a. Cultures were infected with a low MOI of pHSVlac, superinfected with $5 d l 1.2$ at the time of infection, and 2 days (solid circles) or 9 days (solid squares) after gene transfer, the number of cells expressing $\beta$-galactosidase was determined using X-gal staining. Additional cultures were infected with the same low MOI of pHSVlac, superinfected with $5 \mathrm{dl} 1.2$ at 7 days after gene transfer, and 9 days after gene transfer (open squares), the number of cells expressing $\beta$ galactosidase was determined. b. Cultures were infected with pHSVlac (packaged with $5 d l 1.2$ ), and after 2 days (1st bar) or 9 days (last 3 bars), $\beta$-galactosidase expression was assayed using $\mathrm{X}$ gal staining. Of the 3 sample sets assayed after 9 days, the first was stained with no additional treatments, while the second and third sets were superinfected with $1 \times 10^{5} \mathrm{pfu}$ of $5 \mathrm{dll} .2$ (+ $5 d l 1.2)$ or $1 \times 10^{5} \mathrm{pfu}$ of D30EBA (+ D30EBA), respectively. Both superinfections were done 2 days before X-gal staining (7 days after infection). The mean number of $\mathrm{X}$-gal positive cells in 3 cultures is shown, and the error bars indicate the standard error of the mean. 
stongly influenced by HSV-1 gene expression. Another possibility is that the IE $4 / 5$ promoter is affected by factors carried within HSV-1 particles, such as the VP16 transactivator protein, and that the amounts of these factors or their stabilities differ between the different mutant helper virus particles.

\section{Rescue of $\beta$-Galactosidase Expression by Superinfection with $5 d l 1.2$}

We reasoned that if the decrease in the number of $\beta$-galactosidase positive cells with time after infection with pHSVlac was due to inactivation of the IE 4/5 promoter, then it might be possible to rescue recombinant gene expression by superinfection with $5 d l 1.2$; in contrast, the death of cells harboring pHSVlac would preclude the rescue of gene expression by superinfection with $5 d l 1.2$. Cultures were infected at a low MOI with pHSVlac packaged with $5 d l 1.2$. Immediately or 7 days later, the cultures were superinfected with increasing amounts of $5 d l 1.2$, and the number of $\beta$-galactosidase positive cells was assayed 2 and 9 days after gene transfer (Figure 7a). When cells were superinfected at the same time as infection with pHSVlac, an increase in the number of positive cells was observed after 2 days, but not after 9 days. However, superinfection with $5 d l 1.2$ at 7 days after gene transfer resulted in an increase in the number of cells expressing $\beta$-galactosidase at 9 days after gene transfer. To investigate if the IE 3 gene product was required for rescue of recombinant gene expression, cultures were infected with pHSVlac packaged with either $5 d l 1.2$ or D30EBA and superinfected at 7 days after gene transfer with the same helper virus. The number of cells expressing $\beta$-galactosidase was determined at 9 days after gene transfer (Figure 7b). Superinfection with $5 d l 1.2$, but not D30EBA, increased the number of cells expressing $\beta$-galactosidase to levels similar to those observed at 2 days after gene transfer. D30EBA directed only a small increase in the number of cells expressing $\beta$-galactosidase, which may be due to the effects of the VP16 protein contained in HSV-1 particles, whereas the much larger enhancement by $5 d l 1.2$ may be dependent on the IE 3 gene. These results demonstrate that despite a decrease in the level of expression of $\beta$-galactosidase in some cells, functional pHSVlac DNA persists in most infected cells for at least 1 week and remains responsive to transactivating factors.

\section{DISCUSSION}

Defective HSV-1 vectors packaged with D30EBA have been used in physiological experiments $(1,2,9,10,15,19$, 36). However, there are a number of difficulties in working with the D30EBA packaging system. When vectors are packaged using D30EBA in M64A cells, revertants to wt HSV-1 arise at a frequency of between $10^{-5}$ and $10^{-4}$. In addition, when using D30EBA as the helper virus grown on either M64A or RR1 cells, the resulting virus stocks do not consistently contain either a high titer of vector $\left(\geq 10^{6} / \mathrm{mL}\right)$ or a good ratio of vector to helper virus $(\geq 1)$. The packaging system described in this report, which uses $5 d l 1.2$ virus (23) grown on 2-2 cells (31), consistently produces virus stocks with undetectable levels of wt HSV-1 $\left(<10^{-6}\right)$ and both a high titer of vector $\left(\geq 10^{6} / \mathrm{mL}\right)$ and a high ratio of vector to helper $(\geq 1)$. The reasons for this are not completely clear but may be related to the efficient growth of $5 d l 1.2$ on $2-2$ cells. The titers of $5 \mathrm{dll} 1.2$ obtained in tissue culture do not differ significantly from the titers of wt HSV-1 (23), whereas the titers of D30EBA and d120 obtained following growth on the appropriate cell line are decreased by at least 1 order of magnitude compared with wt HSV-1 $(6,27)$.

The stability of expression of $\beta$ galactosidase from pHSVlac was examined in cultured cortical cells. At one week after gene transfer, the number of cells expressing high levels of $\beta$ galactosidase was approximately $30 \%$ of that observed at 2 days after gene transfer, regardless of the helper virus used for packaging. Superinfection with $5 d l 1.2$ directed a transient increase in the number of cells expressing high levels of $\beta$-galactosidase, and this procedure was used to demonstrate the persistence of pHSVlac DNA in these cells for 1 week. We have begun similar experiments in the adult rat brain, and preliminary results indicate that most of the cells receiving HSV-1 vectors do not support high-level, long-term expression, although HSV-1 vectors persist in these cells for months, and the level of expression can be elevated by superinfection with $5 d l 1.2$.

The primary reason for the decline in the level of recombinant gene expression in some cultured cortical cells is a decrease in promoter activity, although the mechanism mediating this change in promoter activity is not clear. In the HSV-1 genome, the IE 4/5 promoter is active only during the immediate-early and early phases of lytic infection and is down-regulated during the late phase (reviewed in References 34 and 35). Furthermore, IE promoters appear to be silent during the latent state (reviewed in Reference 33). However, in transgenic mice containing the lac $Z$ gene regulated by the IE 3 promoter, constitutive expression of $\beta$-galactosidase is observed in many cell types, both inside and outside of the nervous system $(24,25)$. Constitutive expression of a recombinant gene product, although at low levels, is also observed in fibroblast cell lines stably transfected with the IE 3 promoter (26). Infection of cultured sensory neurons with defective HSV-1 vectors that use the IE 1 , IE 3 or IE $4 / 5$ promoters results in longterm (10 week) expression with little decline in the number of cells expressing $\beta$-galactosidase compared to earlier times (2 weeks) (32). However, as described in this report, the number of cultured cortical cells showing gene expression from the IE $4 / 5$ promoter declines to about $30 \%$ after one week. One possible explanation for these results is that there are tissue-specific factors required to support long-term gene expression from the IE $4 / 5$ promoter. Thus, in some cell types (e.g., cortical neurons), the IE $4 / 5$ promoter is only activated transiently by factors associated with viral infection, while in other cell types (e.g., sensory neurons), further activation of the IE 4/5 promoter by cellular factors allows continued gene expression. On the other hand, heterologous promoters may also be subject to inhibitory influences by HSV-1 sequences. Consistent with this explanation, insertion of the murine leukemia virus long terminal repeat (LTR) promoter into the HSV-1 genome 
results in long-term expression in the peripheral nervous system but only transient expression in motor neurons of the hypoglossal nucleus (8). These results indicate an inhibitory effect of the HSV-1 genome on a promoter that often supports constitutive expression in other experimental contexts. Results using a defective HSV vector containing the preproenkephalin promoter in the adult rat brain indicate that it can direct some expression of the lac $Z$ gene for up to 2 months (21), but no quantitative data are yet available on the stability of gene expression. Our preliminary experiments using vectors containing other cellular promoters indicate a gradual reduction in the number of cells supporting high-level recombinant gene expression. These HSV-1 vectors contain the HSV-1 ori and $\mathbf{a}$ sequences, and it is possible that there are still regulatory elements present in these viral sequences which can reduce in gene expression. Alternatively, events associated with the viral mode of entry into the cell may cause cellular responses that could direct a gradual reduction in gene expression, regardless of the promoter in the defective HSV-1 vector. In view of our observation that recombinant gene expression may be reactivated even after promoter shutdown, it will be interesting to observe the behavior of an inducible promoter (17) within the context of defective HSV-1 vectors.

Using the $5 d l 1.2$ virus $2-2$ cell line packaging system described here, we can consistently produce high-titer vector stocks with low proportions of helper virus and undetectable levels of wt HSV-1. Furthermore, pHSVlac packaged with this system can support long-term (1 week) expression in some cultured cortical cells, although promoter activity is decreased in other cells. The observation that functional defective HSV-1 vector DNA can persist in neurons in a quantitative and long-term manner indicates that this vector system has the potential to support high-level, long-term gene expression. The properties of the $5 \mathrm{dll} 1.2$ virus 2-2 cell line packaging system, in particular the high vector titers, should facilitate studies applying HSV-1 vectors both to gene therapy and to questions in neuronal physiology.

\section{ACKNOWLEDGMENTS}

We are grateful to Drs. R.D. Everett, N.D. Stow, P.A. Sčhaffer, R.M. SandriGoldin and P.A. Johnson for viruses and/or cell lines. We thank Drs. C. Fraefel, J.A. Majzoub, W.J. Mitchell, C.L. Wilcox and R. Neve for sharing unpublished data and/or their comments on the manuscript.

This work was supported by AG10827 (NIH), the American Health 
Assistance Foundation, the Burroughs Wellcome Fund and the National Parkinson Foundation (AIG); MH09823 (NIH) and the French Foundation (DH); and the Pharmaceutical Manufacturers Foundation (SS).

\section{REFERENCES}

1.Battleman, D.S., A.I. Geller and M.V. Chao. 1993. HSV-1 vector-mediated gene transfer of the human nerve growth factor receptor p75hNGFR defines high-affinity NGF binding. J. Neurosci. 13:941-951.

2.Bergold, P.J., P. Casaccia-Bonnefil, X.L. Zeng and H.J. Federoff. 1993. Transsynaptic neuronal loss induced in hippocampal slice cultures by a herpes simplex virus vector expressing the GluR6 subunit of the kainate receptor. Proc. Natl. Acad. Sci. USA 90:61656169

3.Brown, S.M., D.A. Ritchie and J.H. SubakSharpe. 1973. Genetic studies with herpes simplex virus type 1 . The isolation of temperature-sensitive mutants, their arrangement into complementation groups and recombination analysis leading to a linkage map. J. Gen. Virol. 18:329-346.

4.Choi, H.K., L. Won, J.D. Roback, B.H. Wainer and A. Heller. 1992. Specific modulation of dopamine expression in neuronal hybrid cells by primary cells from different brain regions. Proc. Natl. Acad. Sci. USA 89:89438947.

5.Davidson, I. and N.D. Stow. 1985. Expression of an immediate early polypeptide and activation of a viral origin of DNA replication in cells containing a fragment of herpes simplex virus DNA. Virology 141:77-88.

6.DeLuca, N.A., A.M. McCarthy and P.A. Schaffer. 1985. Isolation and characterization of deletion mutants of herpes simplex virus type 1 in the gene encoding immediate-early regulatory protein ICP4. J. Virol. 56:558-570.

7.DeLuca, N.A. and P.A. Schaffer. 1987. Activities of herpes simplex virus type 1 (HSV-1) ICP4 genes specifying nonsense peptides. Nucleic Acids Res. 15:4491-4511.

8.Dobson, A.T., T.P. Margolis, F. Sedarati, J.G. Stevens and L.T. Feldman. 1990. A latent, nonpathogenic HSV-1-derived vector stably expresses beta-galactosidase in mouse neurons. Neuron 5:353-360.

9.During, M.J., J.R. Naegele, K.L. O'Malley and A.I. Geller. 1994. Long-term behavioral recovery in Parkinsonian rats by an HSV vector expressing tyrosine hydroxylase. Science 266:1399-1403.

10.Federoff, H.J., M.D. Geschwind, A.I. Geller and J.A. Kessler. 1992. Expression of nerve growth factor in vivo from a defective herpes simplex virus 1 vector prevents effects of axotomy on sympathetic ganglia. Proc. Natl. Acad. Sci. USA 89:1636-1640.

11.Fink, D.J., L.R. Sternberg, P.C. Weber, M. Mata, W.F. Goins and J.C. Glorioso. 1992. In vivo expression of beta-galactosidase in hippocampal neurons by HSV-mediated gene transfer. Hum. Gene Ther. 3:11-19.

12.Geller, A.I. 1991. A system, using neural cell lines, to characterize HSV-1 vectors containing genes which affect neuronal physiology, or neuronal promoters. J. Neurosci. Methods 36:91-103.

13.Geller, A.I. 1991. Influence of the helper virus on expression of beta-galactosidase from a defective HSV-1 vector, pHSVlac. J. Virol. Methods 31:229-238.

14.Geller, A.I. and X.O. Breakefield. 1988. A defective HSV-1 vector expresses Escherichia coli beta-galactosidase in cultured peripheral neurons. Science 241:1667-1669.

15.Geller, A.I., M.J. During, J.W. Haycock, A. Freese and R. Neve. 1993. Long-term increases in neurotransmitter release from neuronal cells expressing a constitutively active adenylate cyclase from a herpes simplex virus type 1 vector. Proc. Natl. Acad. Sci. USA 90:7603-7607.

16.Geller, A.I., K. Keyomarsi, J. Bryan and A.B. Pardee. 1990. An efficient deletion mutant packaging system for defective herpes simplex virus vectors: potential applications to human gene therapy and neuronal physiology. Proc. Natl. Acad. Sci. USA 87:89508954.

17.Gossen, M. and H. Bujard. 1992. Tight control of gene expression in mammalian cells by tetracycline-responsive promoters. Proc. Natl. Acad. Sci. USA 89:5547-5551.

18.Greene, L.A. and A.S. Tischler. 1976. Establishment of a noradrenergic clonal line of rat adrenal pheochromocytoma cells which respond to nerve growth factor. Proc. Natl. Acad. Sci. USA 73:2424-2428.

19.Ho, D.Y., E.S. Mocarski and R.M. Sapolsky. 1993. Altering central nervous system physiology with a defective herpes simplex virus vector expressing the glucose transporter gene. Proc. Natl. Acad. Sci. USA 90:36553659.

20.Johnson, P.A., A. Miyanohara, F. Levine, T. Cahill and T. Friedmann. 1992. Cytotoxicity of a replication-defective mutant of herpes simplex virus type 1. J. Virol. 66:2952-2965.

21.Kaplitt, M.G., A.D. Kwong, S.P. Kleopoulos, C.V. Mobbs, S.D. Rabkin and D.W. Pfaff. 1994. Preproenkephalin promoter yields region-specific and long-term expression in adult brain after direct in vivo gene transfer via a defective herpes simplex viral vector. Proc. Natl. Acad. Sci. USA 91:89798983.

22.Koh, J.Y. and D.W. Choi. 1987. Quantitative determination of glutamate mediated cortical neuronal injury in cell culture by lactate dehydrogenase efflux assay. J. Neurosci. Methods 20:83-90.

23.McCarthy, A.M., L. McMahan and P.A. Schaffer. 1989. Herpes simplex virus type 1 ICP27 deletion mutants exhibit altered patterns of transcription and are DNA deficient. J. Virol. 63:18-27.

24.Mitchell, W.J. 1994. Neurons differentially control activation of the HSV-1 ICP4 promoter in transgenic mice [abstract]. The 19th International Herpesvirus Workshop, Vancouver, BC, Canada. Abstract No. 315

25.Mitchell, W.J., P. Gressens, J.R. Martin and R. DeSanto. 1994. Herpes simplex virus type 1 DNA persistence, progressive disease and transgenic immediate early gene promoter ac- tivity in chronic corneal infections in mice. $\mathrm{J}$. Gen. Virol. 75:1201-1210.

26.Mosca, J.D., G.R. Reyes, P.M. Pitha and G.S. Hayward. 1985. Differential activation of hybrid genes containing herpes simplex virus immediate-early or delayed-early promoters after superinfection of stable DNAtransfected cell lines. J. Virol. 56:867-878.

27.Paterson, T. and R.D. Everett. 1990. A prominent serine-rich region in Vmw175, the major transcriptional regulator protein of herpes simplex virus type 1 , is not essential for virus growth in tissue culture. J. Gen. Virol. $71: 1775-1783$.

28.Persson, R.H. and S. Bacchetti. 1987. In cell lines constitutively synthesizing a temperature-sensitive ICP4 protein of herpes simplex virus type 1, amount and function of ICP4 are both regulated by temperature. Virology 158:285-293.

29.Sanes, J.R., J.L.R. Rubenstein and J.F. Nicolas. 1986. Use of a recombinant retrovirus to study post-implantation cell lineage in mouse embryos. EMBO J. 5:3133-3142.

30.Schaffer, P.A., V.C. Carter and M.C. Timbury. 1978. Collaborative complementation study of temperature-sensitive mutants of herpes simplex virus types 1 and 2 . Virology 27:490-504.

31.Smith, I.L., M.A. Hardwicke and R.M. Sandri-Goldin. 1992. Evidence that the herpes simplex virus immediate early protein ICP27 acts post-transcriptionally during infection to regulate gene expression. Virology 186:74-86.

32.Smith, R.L., A.I. Geller, K.W. Escudero and C.L. Wilcox. 1995. Long-term expression in sensory neurons in tissue culture from herpes simplex virus type 1 (HSV-1) promoters in an HSV-1-derived vector. J. Virol. 69:4593-4599.

33.Spaete, R.R. and N. Frenkel. 1982. The herpes simplex virus amplicon: a new eucaryotic defective-virus cloning-amplifying vector. Cell 30:295-304.

34.Spear, P.G. and B. Roizman. 1981. Herpes simplex viruses, p. 615-746. In J. Tooze (Ed.), DNA Tumor Viruses. Cold Spring Harbor Laboratory, Cold Spring Harbor, NY.

35.Ward, P.L. and B. Roizman. 1994. Herpes simplex genes: the blueprint of a successful human pathogen. Trends Genet. 10:267-274.

36.Xu, H., H. Federoff, J. Maragos, L.F. Parada and J.A. Kessler. 1994. Viral transduction of trkA into cultured nodose and spinal motor neurons conveys NGF responsiveness. Dev. Biol. 163:152-161.

Received 1 May 1995; accepted 6 September 1995.

Address correspondence to:

Filip Lim

Centro de Biologia Molecular

Facultad de Ciencias

Universidad Autonoma de Madrid

E-28049 Cantoblanco

Spain

Internet:flim@mvax.cbm.uam.es 